\title{
Article \\ Application of Noise Certification Regulations within Conceptual Aircraft Design
}

\author{
Michel Nöding and Lothar Bertsch * (iD \\ German Aerospace Center (DLR), Institute of Aerodynamics and Flow Technology, 37075 Göttingen, Germany; \\ michel.noeding@dlr.de \\ * Correspondence: lothar.bertsch@dlr.de
}

Citation: Nöding, M.; Bertsch, L. Application of Noise Certification Regulations within Conceptual Aircraft Design. Aerospace 2021, 8, 210. https://doi.org/10.3390/ aerospace 8080210

Academic Editor: Michael Kokkolaras

Received: 16 July 2021

Accepted: 28 July 2021

Published: 3 August 2021

Publisher's Note: MDPI stays neutral with regard to jurisdictional claims in published maps and institutional affiliations.

Copyright: (c) 2021 by the authors Licensee MDPI, Basel, Switzerland. This article is an open access article distributed under the terms and conditions of the Creative Commons Attribution (CC BY) license (https:// creativecommons.org/licenses/by/ $4.0 /)$.

\begin{abstract}
ICAO Annex 16 regulations are used to certify the acoustic performance of subsonic transport aircraft. Each aircraft is classified according to the measured EPNL levels at specific certification locations along the approach and departure. By simulating this certification process, it becomes possible to identify all relevant parameters and assess promising measures to reduce the noise certification levels in compliance with the underlying ICAO regulations, i.e., allowable operating conditions of the aircraft. Furthermore, simulation is the only way to enable an assessment of novel technology and non-existing vehicle concepts, which is the main motivation behind the presented research activities. Consequently, the ICAO Annex 16 regulations are integrated into an existing noise simulation framework at DLR, and the virtual noise certification of novel aircraft concepts is realized at the conceptual design phase. The predicted certification levels can be directly selected as design objectives in order to realize an advantageous ICAO noise category for a new aircraft design, i.e., simultaneously accounting for the design and the resulting flight performance. A detailed assessment and identification of operational limits and allowable flight procedures for each conceptual aircraft design under consideration is enabled. Sensitivity studies can be performed for the relevant input parameters that influence the predicted noise certification levels. Specific noise sources with a dominating impact on the certification noise levels can be identified, and promising additional low-noise measures can be applied within the conceptual design phase. The overall simulation process is applied to existing vehicles in order to assess the validity of the simulation resultsfcompared to published data. Thereafter, the process is applied to some DLR low-noise aircraft concepts to evaluate their noise certification levels. These results can then be compared to other standard noise metrics that are typically applied in order to describe aircraft noise, e.g., SEL isocontour areas. It can be demonstrated that certain technologies can significantly reduce the noise impact along most of an approach or departure flight track but have only a limited influence on the noise certification levels and vice versa. Finally, an outlook of the ongoing developments is provided, in order to apply the new simulation process to supersonic aircraft. Newly proposed regulations for such concepts are implemented into the process in order to evaluate these new regulations and enable direct comparison with existing regulations.
\end{abstract}

Keywords: aircraft noise simulation; conceptual aircraft design; noise certification; ICAO Annex 16; PANAM; RCE

\section{Introduction}

In order to fully exploit novel technologies and specific measures to minimize aircraft noise, it is essential to incorporate noise prediction early within the conceptual aircraft design phase, e.g., see Reference [1]. Only at this early stage is the degree of freedom in available design and technology choices large enough to really enforce a low-noise aircraft design. Furthermore, the incorporation of all relevant disciplines within one simulation process enables all snowball effects that are caused by any modification to the aircraft, engine, or flight procedure to be accounted for, which affects all other related disciplines. 
For example, any modification to a component design will not only affect a specific noise source on board but can also determine the flight performance of the final vehicle, e.g., as demonstrated in Reference [2]. According to the underlying flight performance along the approach and departure, the operating condition, and hence, the noise generation of each noise source, is directly and significantly affected. It becomes clear that any modification to a noise source on-board the aircraft, without consideration of its implications on the flight performance, will not result in realistic and physics-based results. These strong interdependencies have to be considered for each and every design or technology option under consideration; hence, a full approach-and-departure flight simulation is a prerequisite to any meaningful noise assessment of any new design or technology. Depending on the selected design objectives or noise metrics, the computational demands can be significantly increased, e.g., high computational costs can be expected if widespread noise contour areas are evaluated along the entire approach and departure flights for each design or technology option. The computational costs of such noise simulations for the overall aircraft typically scales linearly with the number of flight points along a simulated trajectory, multiplied by the number of observer locations on the ground, e.g., Reference [1]. The evaluation of a contour area (tens of thousands of grid points) along a realistic flight procedure (hundreds of flight points) for each and every vehicle option (hundreds of design variants, e.g., parameter variation of certain design parameters) will quickly scale up and can only be realized at an early design phase, when simple and fast simulation methods are still applicable. In addition to the above-mentioned determination of the noise immission along individual flights, e.g., assessment on the basis of footprints, the certification levels are of great importance, because the classification into different noise chapters also results in additional direct operating costs, e.g., through increased noise-related take-off and landing fees at certain airports, or severe disadvantages related to potential limitations of the number of flights or operating hours. Therefore, manufacturers as well as airlines are interested in an early and reliable prediction of such levels.

In addition, ICAO noise certification levels are simulated for a fraction of the computational costs compared to a full contour area assessment. In this case, only a few observer locations and shortened segments of the full approach-and-departure flight have to be simulated and assessed. Consequently, certification noise levels only capture a very limited and localized situation, and are not representative of the widespread noise exposure along the entire approach-and-departure flights. However, these certification levels can be used as initial noise indicators and are particularly suitable for a quick but coarse comparison of different aircraft designs and technologies due to their standardized form [3]. The use of simulated certification levels as design objectives in the context of low-noise aircraft design has been demonstrated by other researchers, e.g., NASA's N + 1 [4], N + 2 [5], and $\mathrm{N}+3[6,7]$ studies.

In general, a simulation of certification levels is essential, since any new vehicle would be subject to an ICAO noise certification procedure, and hence has to comply with the underlying regulations and limitations. Although computational demand is significantly reduced for an assessment of the certification situation, i.e., there are only three specific ground locations, simple and fast methods at the conceptual design phase still would be required when evaluating different technologies, aircraft designs, and flight procedures. According to Annex 16 [3], specific regulations and limitations are defined with respect to aircraft noise certification. Specific constraints, e.g., ambient weather conditions, and certain flight conditions are defined and have to be enforced when simulating the flight trajectories. To enable a feasible and physics-based assessment of the noise certification levels, vehicle design (source characteristics) and resulting flight performance (operating conditions) have to be accounted for simultaneously. Thereby, it is necessary to account for source characteristics and operating conditions along relevant parts of the approach-and-departure flight procedure, i.e., it can be demonstrated that at least the so-called $10 \mathrm{~dB}$-down time has to be considered in order to adequately capture the certification levels [8,9]. 
Based on existing DLR software tools, and considering the ICAO regulations, a dedicated and fully automated simulation process has been assembled to realize a simulated noise certification $[8,9]$. The new and fully automated simulation process predicts certification levels within the conceptual aircraft design. The ICAO regulations can be assessed based on the available data within the simulation process. The underlying process of assessing the certification is complex and consists of (1) a detailed simulation of the flight path under the given constraints, (2) calculation of the sound emission based on the operating conditions and configurational parameters prevailing in proximity to the certification measurement points, and (3) the modeling of the sound propagation and ground attenuation effects. With this new simulation process, noise certification levels can now be predicted for both existing and novel aircraft concepts. The resulting cumulative noise levels can be directly processed as an optional design objective within the conceptual aircraft design. Different sensitivities of flightpath or design parameters on the certification noise can be investigated simulateously for the first time in one overall simulation process. Predictions for existing vehicles can be compared to published and available data in order to verify the simulation results. It should be noted that the presented activities at DLR do not aim to create a virtual replacement of the actual certification process. The goal of the presented activities is to provide reliable estimates of certification levels to enable a direct comparison of different technologies and designs. Furthermore, comparison to other simulation activities based on certification noise levels is enabled, e.g., research activities at NASA [4-7]. Furthermore, the certification assessment does enable quick comparative studies within the conceptual aircraft design, where significant variations in aircraft design, engine design, selected technology modifications, and flight performance are still realizable, and hence open up a huge solution space.

The prevailing certification regulations, according to the International Civil Aviation Organization (ICAO), are assessed and summarized in the next section of this article. Thereafter, the newly developed simulation process is described in more detail, i.e., Section 2. A verification of the simulation process and a detailed comparison of simulation results and official certification data are presented in Sections 2 and 4.1, respectively. The remaining differences between simulation results and official certification levels can be attributed to several effects that are discussed in Section 4.2. The novel process is finally applied to novel aircraft concepts, and the results of this investigation are presented in Section 5. Furthermore, suggested modifications to the existing regulations in order to enable an assessment of supersonic transport aircraft are presented in the application section. Finally, the findings of this study are summarized and discussed in Section 6. A brief outlook on ongoing and future activities in Section 7 completes this article.

\section{ICAO Noise Certification}

Noise certification of subsonic jet aircraft is defined by the International Civil Aviation Organization (ICAO) [10,11]. The ICAO defines different reference procedures and noise limits for different types of aircraft, i.e., mainly dependent on the aircraft maximum takeoff weight (MTOW) and the number of engines. In the following sections, the existing regulations for a subsonic jet aircraft are described. An initial discussion of an FAA proposal towards regulation of supersonic aircraft is addressed in this article. Certification regulations use the Effective Perceived Noise Level (EPNL) at three reference measurement points as a basis. Two of the reference measurement points are evaluated along take-off and one during landing. Different specific limits for the operation of subsonic aircraft are defined when assessing the EPNL at these measurement points. These regulations are finally implemented in the existing simulation process at DLR, e.g., as described in Reference [2], in order to assess the corresponding certification noise level for existing and novel aircraft designs within the conceptual design phase. Ultimately, the certification levels can be selected as design criteria, and hence can be subject to a low-noise optimization of the vehicle design. 
Figure 1 shows these certification measurement points for departure relative to the runway, as specified by the ICAO. The flyover reference noise measurement point $\left(\mathrm{K}_{1}\right)$ is positioned $6500 \mathrm{~m}$ behind the break release point (Point $\mathrm{A}$ ) on the extended runway centerline below the departure flight path.

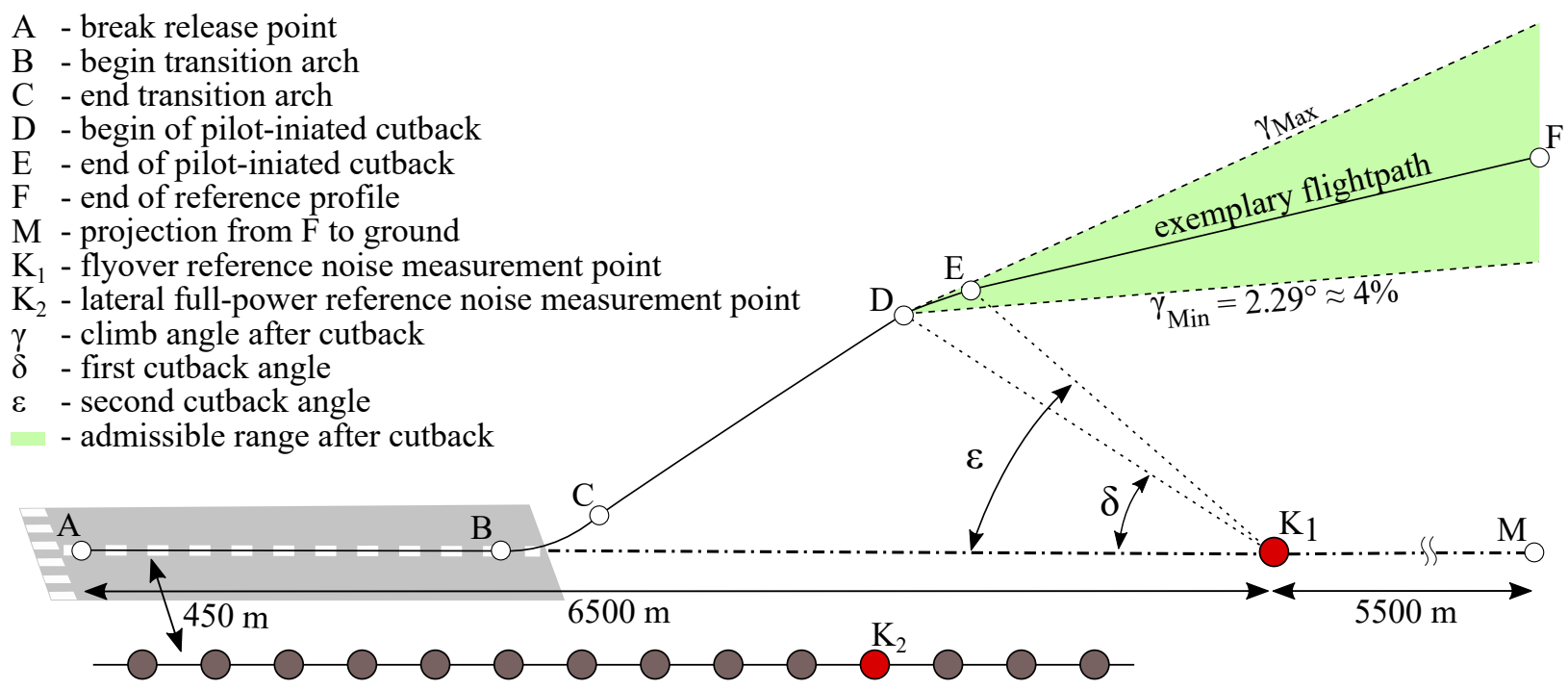

Figure 1. Take-Off Reference profile of subsonic aircraft for noise certification with flyover (K1) and lateral full-power reference measurement point (K2) and runway, adjusted from [3].

In addition, there is a lateral full-power reference noise measurement point $\left(\mathrm{K}_{2}\right)$, located on a line $450 \mathrm{~m}$, parallel to the runway centerline. The position with the highest EPNL along this sideline is selected as the lateral full-power reference noise measurement point. For a valid certification flight, the maximum available thrust must be maintained until a cutback altitude (Point D), dependent on the number of engines, is reached. For a twin-engine aircraft, the cutback height is $300 \mathrm{~m}$, for a three-engine $260 \mathrm{~m}$ and for a fourengine $210 \mathrm{~m}$, above ground. This accounts for the excess thrust that an aircraft with fewer engines has over one with more engines due to the thrust requirements during an engine failure, i.e., One Engine Inoperative (OEI) case. After reaching the respective cutback altitude, the aircraft must climb at least with $4 \%$, which corresponds to a climb angle of approximatly $2.29^{\circ}$. Since the reduction in the engine thrust is not instantaneous, ICAO defines a first and a second cutback angle ( $\delta$ and $\varepsilon$ related to point $\mathrm{K}_{1}$ ) with the points $\mathrm{D}$ and E. Furthermore, the flight must be recorded up to $11 \mathrm{~km}$ (Point F) after the break release point. In addition, there are requirements for the calibrated airspeed at takeoff, defined relative to the aircraft-specific safe takeoff speed V2. The speed V2 +10 knots must be reached as soon as possible after takeoff and the speed V2 +20 knots must not be exceeded during the certification flight. Due to the requirement that the thrust setting be kept constant during calculation of EPNL, the $10 \mathrm{~dB}$-down time must be completed for the lateral measurement point by the time point $\mathrm{D}$ is reached, in case a cutback is performed. For the flyover measurement point, the $10 \mathrm{~dB}$-down time must be between points $\mathrm{E}$ and $\mathrm{F}$ for the same reason.

The noise during approach is evaluated at another measurement point during noise certification, which is shown in Figure 2, together with the specified approach path. The approach flightpath must be recorded from point $\mathrm{G}$, which is $7400 \mathrm{~m}$ in front of the runway landing threshold. The projection of this point on the ground is called point $\mathrm{P}$. This approach reference noise measurement point $\left(\mathrm{K}_{3}\right)$ is located $2000 \mathrm{~m}$ in front of the runway landing threshold (Point $\mathrm{O}$ ) in the extended runway centerline. Taking into account the prescribed glide path of $3^{\circ}$, the aircraft flies over the measurement point at an altitude of $120 \mathrm{~m}$ (Point $\mathrm{H})$, where the aircraft is in a stabilized state and the engine is not idling, as is 
the case in other phases of the approach. It should be noted that an altitude deviation of $20 \%$, i.e., $\pm 24 \mathrm{~m}$, is allowed at Point $\mathrm{H}$. The glide path ends at point $\mathrm{I}$ and the touchdown takes place at point $\mathrm{J}$, about $300 \mathrm{~m}$ behind point $\mathrm{O}$.

The EPNL metric is used for noise certification, and its calculation is explained below.

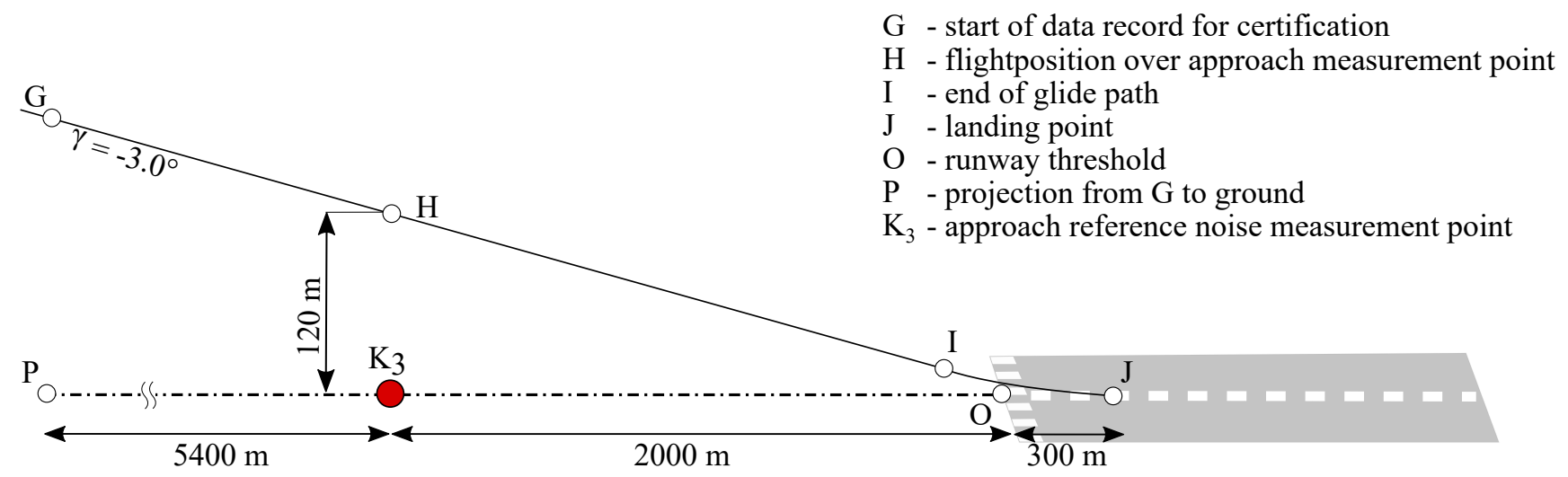

Figure 2. Reference profile of subsonic aircraft for noise certification with approach reference measurement point and runway.

In addition, a chart illustrating the calculation can be found in the Appendix A (Figure A1). At the three measurement points, the Sound Pressure Level (SPL) in the onethird octave band $i$ is measured at intervals of $0.5 \mathrm{~s}$ in a microphone height of $1.2 \mathrm{~m}$ above ground for every timestep $\mathrm{k}$. After frequency weighting of the measured SPL using noy tables into the Perceived Noisiness $n(i, k)$ the individual one-third octave bands are summed over $i$ and, to weight the highest band, the band SPL is multiplied by 0.85 , while the other bands are multiplied by 0.15 . A summation of the one-third octave band spectra gives the Total Perceived Noisiness N(k), which is then converted into the Perceived Noise Level PNL(k). In order to take the sensitivity of human hearing for discrete tones into account, a sound correction $C(k)$ is applied, which adds a sound penalty to the PNL(k) depending on the relative differences between adjacent Sound Pressure Levels of the individual one-third octave bands, which leads to the Tone-Corrected Perceived Noise Level PNLT(k). There is only a penalty when Sound Pressure Level difference between the adjacent bands is above $1.5 \mathrm{~dB}$. Afterwards, the EPNL is calculated by the time integration of all levels of PNLT(k), which are, at most, $10 \mathrm{~dB}$ below the maximum PNLTM. For better comparability, a reference flight procedure is defined under atmospheric reference conditions. The determined EPNL is corrected to this reference procedure by applying different correction terms. In these studies, it is assumed that both the trajectory and atmospheric conditions are simulated to be identical with the reference conditions and, therefore, no correction to the determined EPNL is necessary.

\section{Simulation Environment}

\subsection{Aircraft Design}

Aircraft and engine design was assessed with TU Braunschweig's PrADO (Preliminary Aircraft Design and Optimization) simulation tool [12]. PrADO is an aircraft design synthesis code comprised of individual software modules, which are each assigned to a certain task or discipline within the design process of aircraft and engines [12], e.g., dedicated modules will compute the aircraft mass breakdown based on the selected vehicle layout. PrADO not only accounts for all the individual disciplines but, most importantly, also takes the prevailing interaction effects into consideration, i.e., so-called snow-ball effects. The software modules are executed iteratively until preselected major design parameters reach convergence, e.g., the changes in aircraft component masses per process iteration stay below specified residuals. 
After the convergence of all major design parameters, PrADO yields a valid and physics-based aircraft design that fulfills all the preselected design requirements, i.e., Top Level Aircraft Requirements. Thereby, the individual software modules can straightforwardly be replaced by other modules of higher fidelity or by external data, e.g., measured aircraft component weights. The PrADO tool has been upgraded to provide all the required input data for a subsequent system noise prediction, i.e., including aircraft and engine design parameters and a PrADO flight track [1]. With PrADO, existing aircraft can be simulated, as well as novel aircraft concepts. The process can then be applied to a system noise prediction of arbitrary tube-and-wing aircraft concepts [1].

External input data, such as engine performance maps, geometrical details, or the flight procedure, can be processed via dedicated interfaces in order to improve prediction accuracy if required and available [2]. Simulation results from corresponding software modules within PrADO are then directly replaced by external input data, and the PrADO modules will not be executed. For the noise assessment carried out within this study, such high-fidelity external input data for the engine were provided by the DLR Institute of Propulsion Technology, i.e., the simulation results of their tool GTlab [13]. The flight trajectory by PrADO was replaced by results from the DLR flight simulation tool Flightpath for Noise Analysis (FLIPNA), which is fully compatible with ECAC Doc. 29 regulations. At this point, the aircraft, the engine, and the resulting flight trajectories are completely described and the overall simulation process can be initiated.

\subsection{Flight Simulation}

Based on the complete aircraft description from the updated PrADO process, a detailed assessment of approach and departure procedures is enabled. For the purpose of the certification assessment, a newly developed flight simulation tool Flightpath for Noise Analysis (FLIPNA), e.g., Reference [14], replaces the corresponding PrADO simulation module because it can directly account for the ICAO regulations with respect to the certification rules. Thereby, FLIPNA directly processes the PrADO aircraft and engine output in order to simulate physics-based trajectories. The aircraft trajectory is defined as a series of flight points accounting for varying operational conditions, e.g., variations in engine operation or the usage of landing gear and a high-lift system. Certain control parameters for FLIPNA define the final flight trajectory, and can be varied and selected for optimization, e.g., glide slopes and velocities. At this point, detailed flight trajectories for arbitrary aircraft design can be generated from PrADO. The resulting description of the flight path incorporates all information, as required for a noise prediction with PANAM [14].

\subsection{Noise Prediction}

The overall aircraft noise can be described as the energetic sum of relevant components, i.e., so-called noise sources, and the influence of the most important interdependencies. The software PANAM [1] was developed to realize such a simulation approach, based on the available input data within the conceptual aircraft design process. PANAM is directly operated as a simulation module within PrADO, and will enable a system noise prediction within the design cycle, i.e., modeling the noise emission, transmission, and impact at arbitrary observer locations [1].

PANAM applies semi-empirical, parametric source models that are developed by DLR or adapted from models found in the open literature, i.e., airframe models are developed by DLR [1,15-19], whereas available external engine models have been adapted [20,21]. A list of the models used is given in Table 1. The application of these models yields a directional noise emission prediction in one-third octave bands for one operating condition. PANAM accounts for the individual sources separately. According to the underlying operating condition, the resulting noise source ranking is predicted, which varies significantly along an approach and can vary along a departure. 
If required, noise shielding and refraction effects can be simulated with the DLR tool SHADOW [22]. The predicted noise level differences are then directly processed within PANAM and applied to the corresponding sources, e.g., to account for noise reflection of a landing gear mounted under a large wing surface.

Table 1. PANAM system noise assessment: source models selected for this study.

\begin{tabular}{ll}
\hline Noise Source/Element & Model \\
\hline airframe noise models (airf) & \\
\hline trailing edge & DLR [1,15-19] \\
leading edge & DLR [1,15-17] \\
main landing gear & DLR [1,15-17] \\
nose landing gear & DLR [1,15-17] \\
\hline engine noise models (eng) & \\
\hline fan broadband \& tonal & modified Heidmann [20] \\
jet & modified Stone [21] \\
\hline noise shielding effects (PAA) & \\
\hline- & SHADOW [22] \\
\hline sound propagation effects & \\
\hline- & ISO 9613 [23] \\
\hline ground attenuation effects & \\
\hline- & SAE AIR 1751 [24] \\
\hline
\end{tabular}

Such an emission prediction is then repeated for each individual flight point along a simulated trajectory, e.g., as provided by FLIPNA. The emitted noise from each flight point is then further propagated through the atmosphere, accounting for the prevailing attenuation of the sound, i.e., geometric spreading [25] and atmospheric attenuation [23]. Optionally, ground attenuation effects can be accounted for, to reflect a specific observer situation, i.e., accounting for ground properties and observer details such as height-aboveground of the virtual observer. When reproducing simulating certification conditions, certain options become mandatory, as explained in the next section. The resulting noise from each flight step, as it is received on the ground, can finally be assembled to yield level time-histories and other common noise metrics.

The prediction capabilities of PANAM have been demonstrated for existing aircraft by comparison with experimental data from flyover campaigns, e.g., see Reference [1]. Furthermore, its applicability to novel technology and new aircraft concepts was assessed through a benchmark test of simulation tools from two other large research entities. The results of the benchmark test, as published in Reference [26], show a satisfying agreement and confirm confidence in the PANAM predictions. A direct quantification of the underlying prediction uncertainties is currently under investigation. An earlier study was published in 2019, see Reference [27], to identify and assess the various sources of uncertainty that mpact the overall prediction quality compared to experimental data. Ongoing activities focus on an automated uncertainty quantification within the conceptual aircraft design, i.e., applicable to existing and novel aircraft.

\subsection{Virtual Noise Certification Simulation Process}

It was decided to utilize DLR's distributed simulation environment, the Remote Component Environment (RCE [28]) to realize the virtual noise certification process. The reason for this was the simple applicability and direct availability of such an RCE process within the connected researchers. Aircraft designs and technologies from different groups that are connected to RCE can directly feed and apply the process toward a virtual certification of 
their aircraft concepts. As a mid-term goal, the process is not limited to PrADO designs but for example is also able to process alternative vehicle concepts from the Center of Excellence Sustainable and Energy Efficient Aviation $\left(\mathrm{SE}^{2} \mathrm{~A}\right)$ by TU Braunschweig. Ultimately, the new process can be connected to different aircraft design tools to enable certification noise-related decision making.

The new RCE-based process promises flexibility when updating the simulation with respect to any adjustment to the somewhat antique ANNEX 16 regulations that might be introduced to provide a more realistic representation of aircraft noise around airports. The developed process chain is shown in Figure 3. To investigate the influence of different parameters (e.g., design or flight path parameters), it is possible to specify a parameter variation. A manual modification of individual noise sources is also possible, which allows for an estimatation of the influence of over- and underestimation of individual sources on the certification level. Additionally the effectiveness of targeted noise reduction measures on individual noise sources (e.g., the use of acoustic liners) can be investigated. Based on the definition of the engine and aircraft parameters, the process starts with a calculation of the flight trajectory using the FLIPNA software, on the basis of the previously selected settings. PANAM then uses this trajectory, in conjunction with other necessary input data, and calculates the noise immission at the respective certification measurement point.

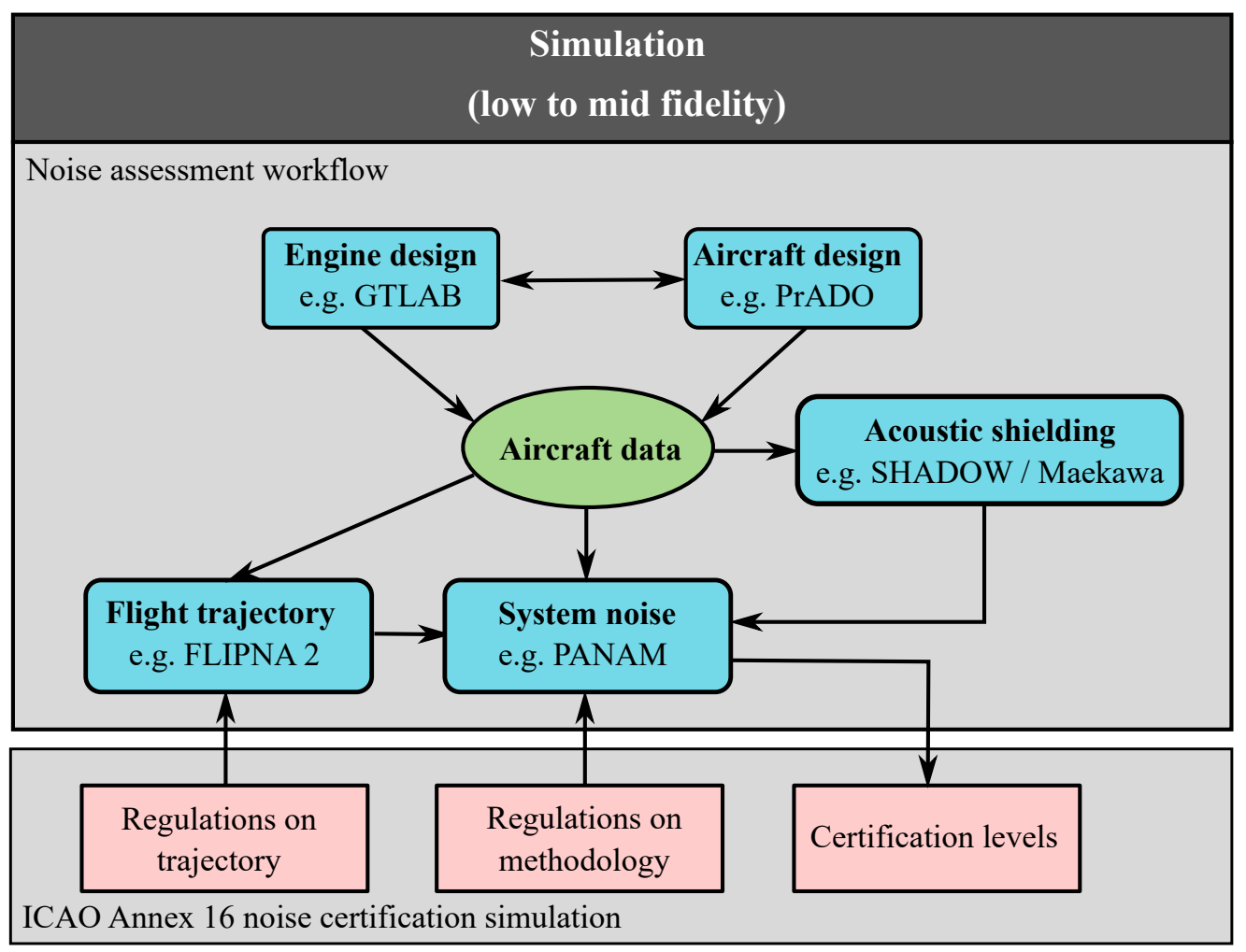

Figure 3. Schematic of the developed process for automated virtual noise certification.

The process automatically determines which parts of the trajectory are considered in EPNL calculation, i.e., where the $10 \mathrm{~dB}$-down time starts and ends. This is supplemented by a consideration of the emission spectrum at the flight position that causes the highest PNLT (called PNLTM). A comparison of the spectra of the individual sources of emission and immission allows for a quick assessment of the influence of sound propagation effects, which have a significant impact on EPNL, e.g., at the flyover measurement point due to the relatively large distance between the source and observer. Finally, the virtual noise certification is performed in accordance with the implemented ICAO specifications (see Section 2). This status quo of the process chain can be used to automatically calculate the certification level of arbitrary aircraft within the framework of the preliminary aircraft design. 


\section{Verification}

The new process was initially applied to two selected aircraft, i.e., a simulation model of an A319-100 powered by two CFM56-5A5 engines (net thrust per engine at sea level $104 \mathrm{kN}$ ) and a B747-400 powered by four CF6-80-C2-B5F engines (net thrust per engine at sea level $272 \mathrm{kN}$ ). An overview of the most important design parameters and the airspeeds used in the certification calculation are summarized in Table 2. The aircraft masses MTOM and MLM were adjusted to the values used and provided in the actual noise certification documents of this aircraft configuration.

Table 2. Data of two investigated aircraft.

\begin{tabular}{lccc}
\hline Parameter & Unit & A319-100 & B747-400 \\
\hline maximum takeoff mass & $\mathrm{kg}$ & 68,000 & 396,893 \\
maximum landing mass & $\mathrm{kg}$ & 61,000 & 285,783 \\
overall length & $\mathrm{m}$ & 33.84 & 70.60 \\
overall height & $\mathrm{m}$ & 12.14 & 19.41 \\
engine type & - & CFM56-5A5 & CF6-80-C2-B5F \\
number of engines & - & 2 & 4 \\
static thrust per engine at sea level & $\mathrm{N}$ & 104,043 & 272,530 \\
bypass ratio & - & 6 & 5 \\
span & - & 33.94 & 64.40 \\
wing reference area & $\mathrm{m}^{2}$ & 122.6 & 561.93 \\
\hline $\mathrm{v}_{\text {Ref }}$ & $\mathrm{m} / \mathrm{s}$ & 65.51 & 68.65 \\
$\mathrm{v}_{\text {Landing }}$ & $\mathrm{m} / \mathrm{s}$ & 70.78 & 73.93 \\
$\mathrm{v}_{\text {Flyover }}$ & $\mathrm{m} / \mathrm{s}$ & 75.13 to 80.13 & 87.90 to 92.89 \\
$\mathrm{~h}_{\text {Cutback }}$ & $\mathrm{m}$ & 300 & 210 \\
\hline
\end{tabular}

The simulation of the two aircraft types results in different cutback heights. A cutback height of $300 \mathrm{~m}$ is predicted for the A319-100, and $210 \mathrm{~m}$ is predicted for the B747-400. To allow for the minimization of certification levels at the flyover measurement point, the lowest allowed cutback height is not used. Instead, the cutback is performed just before the start of the $10 \mathrm{~dB}$-down time of the flyover measurement point, which leads to an increase in cutback height. The later reduction in thrust leads to an increase in flight altitude and, thus, to a reduction in EPNL at the flyover measurement point due to stronger atmospheric propagation attenuation.

Altitude, thrust and calibrated airspeed profiles over the flightpath used to calculate certification levels are shown in Figure 4 for both aircraft. The authors highlight that there is no available information on official noise certification trajectories. Therefore, the trajectories shown and studied here are the result of an optimization to reduce EPNL at the individual measurement points, taking the certification regulations into account. As can be seen, the trajectories of the two aircraft studied differ greatly due to their significant differences in flight performance.

For both aircraft, the lowest certification level at the flyover measurement point was observed when the aircraft operated at the lowest allowed climb angle of $2.29^{\circ}$. Therefore, the relative engine speed could be reduced to $\mathrm{N} 1=73 \%$ (A319-100) and N1 $=95 \%$ (B747-400). In this case, the effect of noise reduction on the ground due to a lower engine thrust outweighs the disadvantage of a reduced distance between source and observer. A variation of the engine thrust after cutback in the allowed range of the regulations showed a change in the certification level of 6.8 EPNdB (A319-100) and 4.9 EPNdB (B747-400) between the highest and lowest value. It is noticeable that the certification level for B747-400 increases abruptly between $\mathrm{N} 1=95$ and $96 \%$, because this change triggers a significant increase in buzzsaw noise according to the implemented fan noise model, as the fan tip Mach number passes 1. 
As previously mentioned, the lateral measurement point with the highest EPNL along the takeoff is identified and selected. This results in a distance to the break release point of $2700 \mathrm{~m}$ for the A319-100 where the aircraft has a flight altitude of $215 \mathrm{~m}$, and for the B747400 of $3600 \mathrm{~m}$ where the aircraft has a flight altitude of $225 \mathrm{~m}$ above ground. The position of the lateral measurement point is strongly dependent on whether the acceleration process on the runway is modeled correctly, so that inaccuracies resulting from aircraft preliminary design can have a large impact. The approach path, not shown here, has a glide path of $3^{\circ}$ with an airspeed of $70.78 \mathrm{~m} / \mathrm{s}(\mathrm{A} 319-100)$ and $73.93 \mathrm{~m} / \mathrm{s}$ (B747-400). The engine thrust is constant along the relevant flight segment and amounts to $43.1 \mathrm{kN}$ (A319-100) and $205.3 \mathrm{kN}$ (B747-400). As specified for certification, the aircraft is simulated at precisely $120 \mathrm{~m}$ above the measurement location.
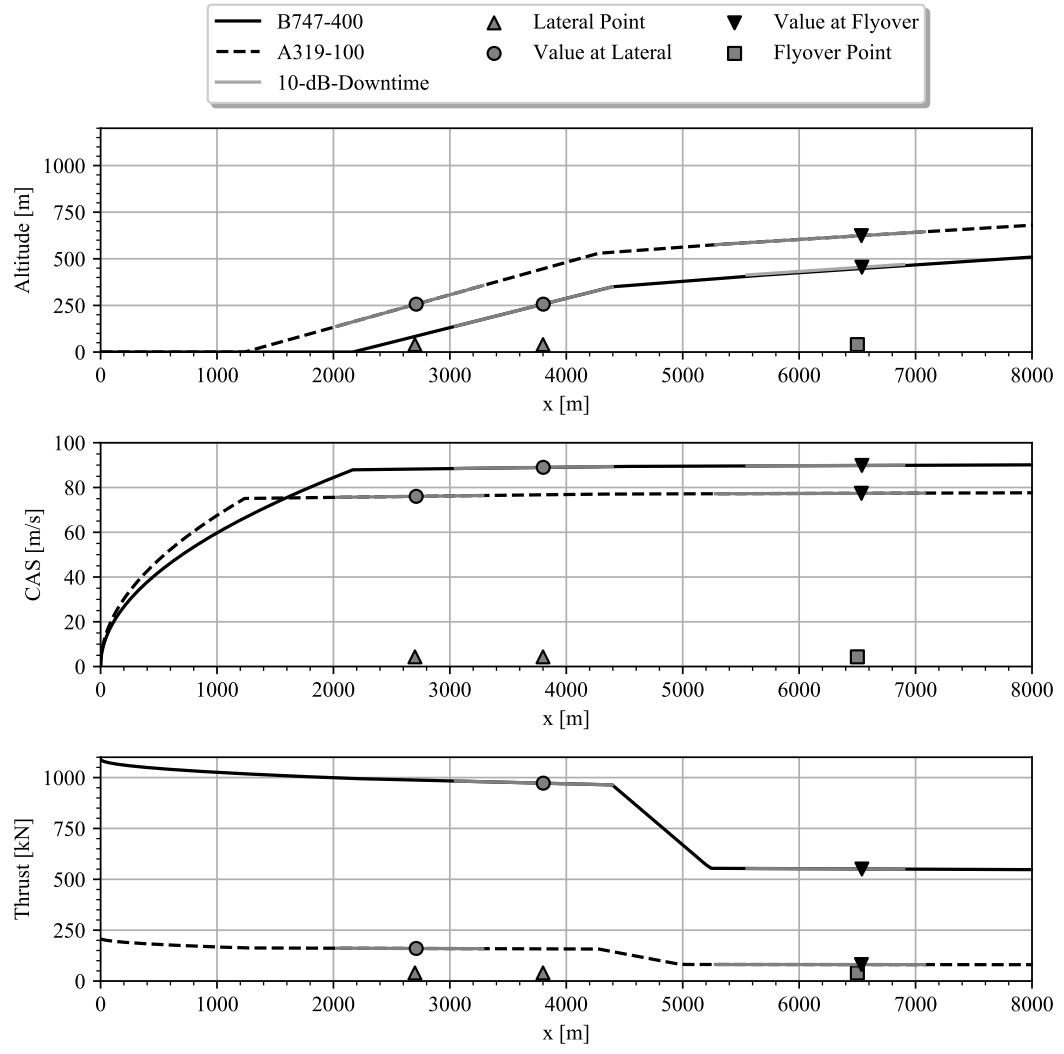

Figure 4. Departure Flightpath with lowest EPNL for virtual noise certification with flyover position and lateral reference meseaurement point.

\subsection{Comparison of Predictions and Published Levels}

Table 3 summarizes a comparison of the certification levels at the three measurement points for the two aircraft examined, with levels that are publicly accessible by European Union Aviation Safety Agency (EASA), see Reference [29]. In contrast to the results presented earlier (DLRK, IB), the acoustic lining routines were adapted and the effects are incorporated into the results. Fan noise contribution was significantly reduced compared to earlier studies, due to the presence of an acoustic lining. There are discrepancies between the official certification levels and the results of this study. Deviations of +3.0 EPNdB (A319100) and +2.8 EPNdB (B747-400) are observed at the flyover position, where certification regulations of flight trajectory are the least stringent. For the approach, reduced deviations to published levels are experienced, i.e., +1.8 EPNdB (A319-100) and +0.8 EPNdB (B747). The differences for the two investigated aircraft, observed at the lateral position, are -3.2 EPNdB (A319-100) and +0.8 EPNdB (B747-400). At this measurement point, a significant influence of the actual ground noise attenuation can be expected due to low elevation angles. This can lead to increasing uncertainties and inaccurate representation 
of the actual conditions of the real certification. The approach situation, according to the regulations, is much more regulated, resulting in a significantly smaller variability in acceptable flight conditions. It can be assumed that the simulated operational input for the noise prediction agrees more with the actual flight conditions of a real test flight for the approach situation, as compared to the departure situation. Other research studies show similar difficulties in predicting measured certification levels in aircraft preliminary design, e.g., Reference [30]. With the exception of the lateral full-power measurement point for A319-100, all simulated certification levels were overestimated relative to the official values. A good agreement is shown for the delta of the individual measurement points when comparing the two aircrafts. There are only significant deviations for the lateral measurement point, where the simplified modeling of the ground influence may play a role, as mentioned previously. In this context, different ground effect models were compared and it was observed that, according to the prevailing ground model, the levels can differ significantly from each other. Therefore, the authors would like to emphasize that the modeling of the ground attenuation effects is currently still associated with a large uncertainty and is part of ongoing research activities. More information on the actual condition, as experienced during the real certification, is not available but would be required for a fair comparison.

Table 3. Comparison of simulated and measured certification levels [29].

\begin{tabular}{lcccc}
\hline Observer Point & A/C & $\begin{array}{c}\text { Simulation } \\
\text { EPNL [EPNdB] }\end{array}$ & $\begin{array}{c}\text { EASA } \\
\text { EPNL [EPNdB] }\end{array}$ & Delta [EPNdB] \\
\hline Flyover & A319-100 & 86.6 & 83.6 & +3.0 \\
Lateral & A319-100 & 90.7 & 93.9 & -3.2 \\
Approach & A319-100 & 96.3 & 94.5 & +1.8 \\
\hline Flyover & B747-400 & 99.4 & 96.6 & +2.8 \\
Lateral & B747-400 & 101.0 & 100.2 & +0.8 \\
Approach & B747-400 & 104.1 & 103.3 & +0.8 \\
\hline
\end{tabular}

\subsection{Discussion of Deviations}

Simulation of the noise certification process and prediction of certification levels for existing aircraft is a very challenging task at the conceptual aircraft design phase. The direct comparison of simulation results to official noise certification data shows deviations in absolute levels which are also experienced by other researchers [30]. Based on the fidelity of the applied simulation tools and the lack of validation data for the flight simulation, this result is not surprising.

The semi-empirical noise source models listed in Table 1 and applied here are inherently associated with modeling uncertainties, e.g., see Reference [27]. Due to their empirical nature, a satisfying agreement between simulation results can be experienced when comparing the results to the measured data of existing aircraft. However, discrepancies are experienced when assessing certification noise levels. This can partially be attributed to the EPNL metric, which is especially sensitive to the spectral shape of the received signal. Obviously, the level of detail associated with the noise source models is not sufficient to precisely resolve the spectral shape for each noise source simulation under every operating condition. A much higher level of fidelity would be required for the simulation methods, which cannot be realized based on the selected models available in the conceptual aircraft design. The selected noise source models were specifically derived to capture standard metrics that are integrated over the frequency spectrum based on a third-octave band resolution. The experienced discrepancies between measured and predicted spectra at distant ground observers are further intensified due to the underlying and simplified sound propagation and ground attenuation models, as specified in Table 1. Ground attenuation is very uncertain, especially due to the microphone height of $1.2 \mathrm{~m}$. A small overestimation of fan tones $(1-2 \mathrm{~dB})$ is possible in preliminary design, but has little to no impact on overall 
levels with conventional metrics such as OASPL; however, such inadequacies may be exacerbated by a greater weighting of the relevant frequency range of fan tones and tonal penalty when using metrics such as EPNL.

In addition to the described modeling challenges for EPNL at the conceptual design phase, the underlying input data introduces additional uncertainties since it originates from low-fidelity simulation at the conceptual aircraft design phase [27]. Especially, the flight trajectory as a direct input for the noise prediction is identified as a major source of uncertainty. In particular, the acceleration of the aircraft on the ground and the thrust setting after cutback, i.e., the actual takeoff trajectory, results in different flight altitudes above the flyover point. It has been demonstrated in various studies that a much better agreement between noise simulation and measured levels can be realized if the operating conditions are provided as an input from the actual flight test. A good agreement between simulation and measurements for metrics other than EPNL is documented for existing aircraft, e.g., Reference [1], if the noise prediction is fed with Flight Data Recorder (FDR) input. The importance of reliable input data is furthermore confirmed by a recent comparison of noise simulation tools between NASA, ONERA, and DLR [26]. It is demonstrated that a good level of agreement between the different tools can be achieved when the input data are clearly defined and kept identical or similar for all simulation tools. Not knowing the actual flight conditions during the certification process, especially for the flyover situation, does not support the direct comparison of absolute levels from simulation and official data. However, predicted level differences between various aircraft types show a much better agreement, supporting a comparative assessment. The reliability of the prediction results for a comparative assessment is furthermore confirmed by the aforementioned simulation tool comparison [26].

To further investigate the significant influence of the flight path on the certification levels, certification levels are predicted based on available flight data for an A319-100 aircraft [31]. The available approach-and-departure flight data from this measurement campaign at the Baltic Airport near Parchim (Germany) are used to calculate the respective certification levels. The available measured noise levels for A-weighted SPL were studied in great detail and show good agreement to the predictions; see Reference [1]. It should be noted that no EPNL measurements are available from this campaign. Due to the underlying motivation behind this flight campaign, no departure flight procedure fully complies with the allowable operating conditions according to the ICAO regulations [3]. The flight altitude above the approach measurement point is too high for approach paths 10 and 12 in Figure 5. This has to be kept in mind when comparing these predictions to the published certification levels. The other approach paths are certification-compliant and show very good agreement with the measured EASA levels. The minor differences between the procedures are due to the slightly different thrust settings and flight altitudes. When comparing with the simulated flight trajectories, it is noticeable that the approach speeds from the FDR data are lower, which lead to lower certification levels. This may indicate that the accuracy of the characteristic speeds in the preliminary design is limited. However, this comparison gives a good indication of the sensitivity of the flight procedures at the certification points, and also can confirm tendencies and trends. As shown in Figure 5, it can be demonstrated that all flight procedures result in higher noise levels at flyover measurement points in comparison with the noise levels published by EASA. Overestimation rates from 0.5 to 3 EPNdB are documented for the flyover situation. Obviously, the differences between the actual flight tracks of the certification and the simulated flights have a great impact. An underestimation of from 1.5 to $2.2 \mathrm{EPNdB}$ at the sideline certification points is observed where the underestimated levels are also experienced when working with the simulated flight procedures. Comparing level differences between the individual flights confirms the expected trends and the applicability of simulation results for a comparative assessment, i.e., see Reference [32].

Another reason for the expected deviations can be identified in the ICAO documentation. Certain correction factors can be applied by the aircraft manufacturers to each of the 
actual noise levels at a certification point. These corrections are mentioned but not further disclosed in the ICAO documentation. The actual levels remain confidential and no further information has to be made available to the public. It is still unclear how these correction factors influence the final and official certification level. If the predicted levels are somewhat higher compared to the official levels, this is understood as a confirmation of the presented simulation results, since it is certain that any additional correction factor applied by an aircraft manufacturer will not further increase the certification levels. Ongoing research activities at DLR and its partners aim towards the quantification of simulation uncertainties for aircraft noise prediction, as applied here, e.g., see Reference [27]. Obviously, this is understood as an essential prerequisite when assessing differences between simulation results and available certification noise levels. However, this research is still ongoing and limited to an uncertainty prediction associated with less complex noise metrics or descriptors, i.e., the maximum A-weighted SPL. The direct application of available uncertainty quantification methods to a complex, frequency-dependent descriptor, including tonal corrections such as the EPNL, e.g., as applied by NASA [7], is not recommended at this moment. Uncertainty quantification associated with complex noise descriptors remains a challenging task for future research activities outside of the presented work.
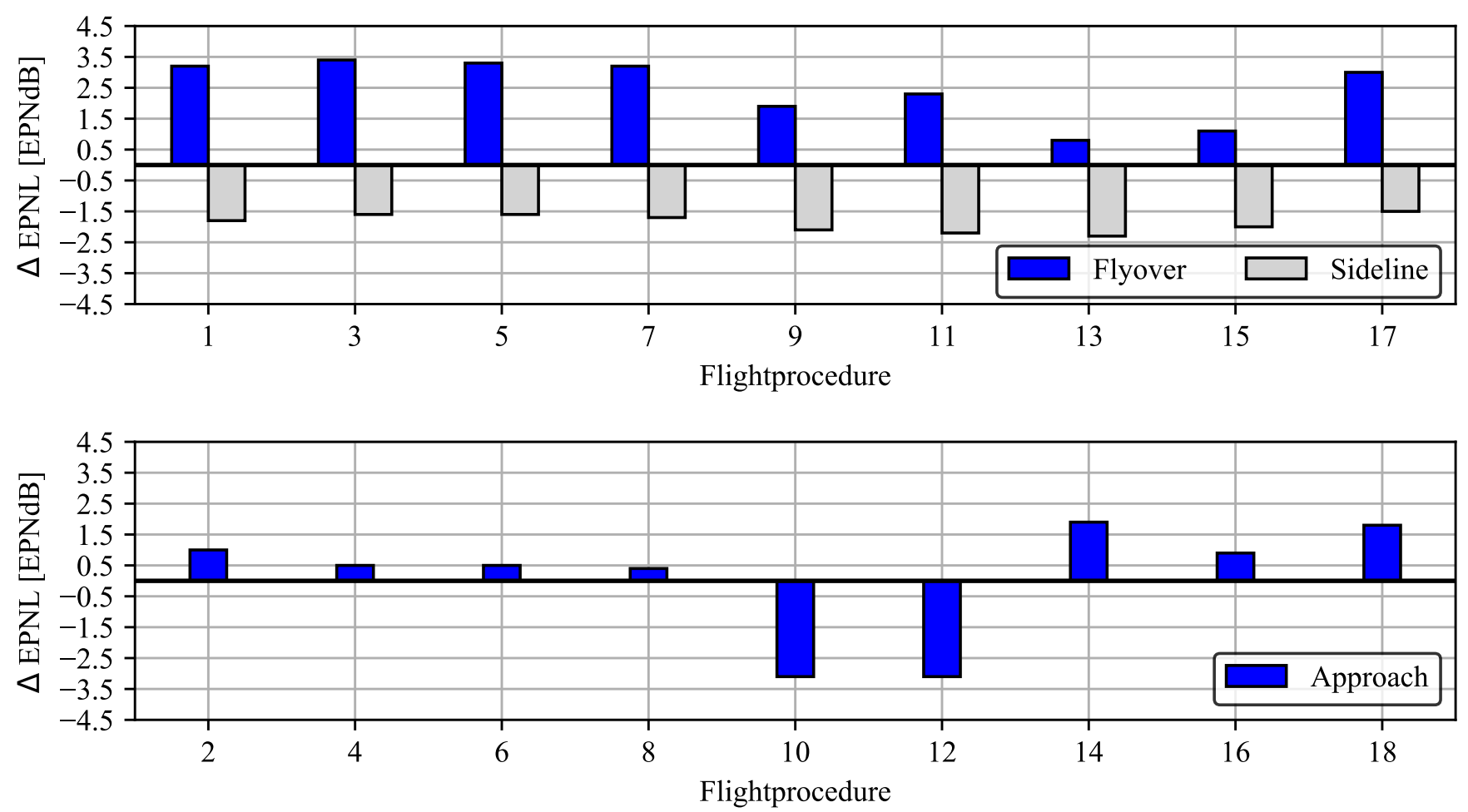

Figure 5. EPNL differences in simulated flight trajectories compared to published certification levels by the EASA.

\subsection{Parameter Sensitivity Study: A319-100}

In order to investigate the influence of the engine and airframe noise sources on the certification level, a sensitivity study of the certification level for A319-100 was performed for each of the three measurement points, starting from the reference case shown above. For this purpose, the predicted noise levels for engine and airframe components were artificially increased/reduced in the range from -9 to $+9 \mathrm{~dB}$. It was assumed that the level difference is equally applied over the entire frequency range.

The plots shown in Figure 6 represent the change in certification level relative to the reference case as a combination of the change in the Sound Pressure Level of the engine and airframe. 
The blue lines show the change in certification level due to the changes applied to the engine, and the green lines show the change in certification level due to changes applied to the airframe contribution, with all other noise sources held constant.
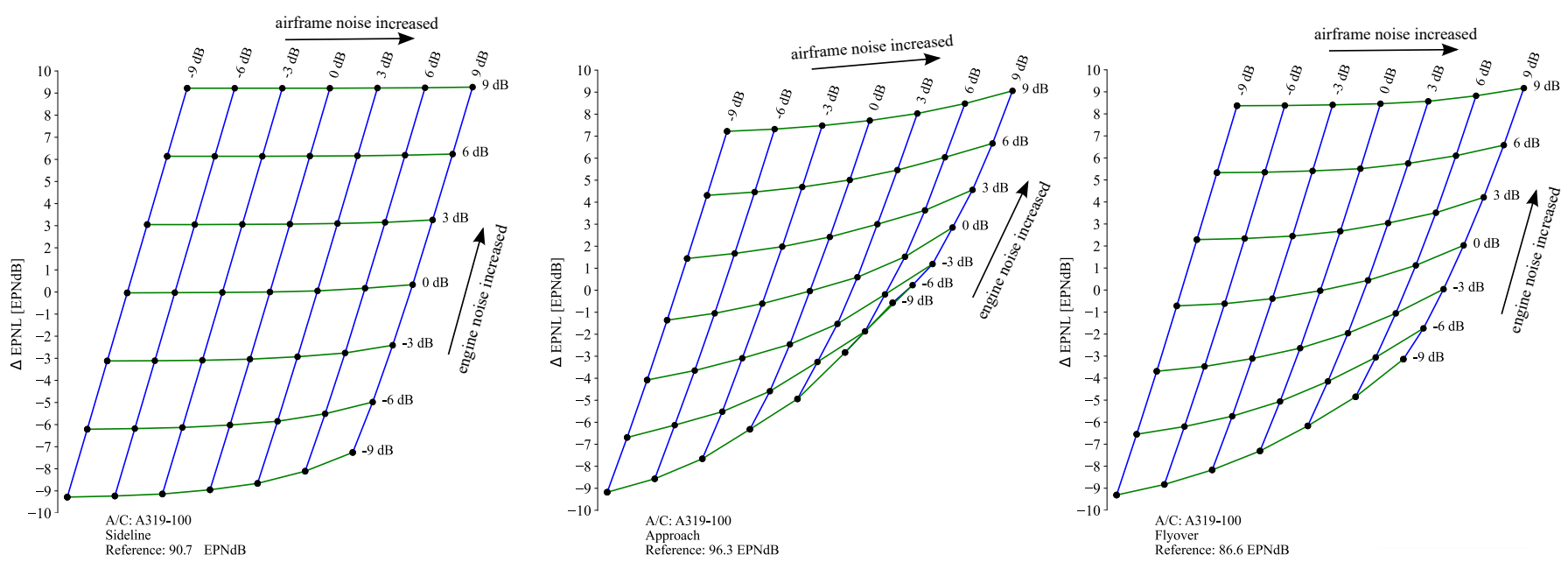

Figure 6. EPNL: sensitivity with respect to airframe and engine noise contribution for sideline (left), approach (middle) and flyover (right).

First, it can be shown that the noise sources of the engine dominate the immission at all three measurement points considered. For conventional tube-and-wing aircraft with turbofan engines, as considered here, airframe noise contribution is also insignificant at the approach certification noise measurement point. During its final approach, the flight segment increased-engine thrust settings are required to compensate the drag of deployed high-lift elements and landing gear while maintaining a prescribed flight velocity. Consequently, the engine noise clearly and constantly dominates the airframe noise contribution at the approach measurement point. Engine noise would have to be reduced drastically in order to see any impact of the airframe noise sources on the approach certification noise level, e.g., Figure 6. Consequently, for an efficient reduction in certification levels, noise abatement measures at the engine should be considered first; a quiet airframe would only after a drastic engine noise reduction. For the B747-400, the results are qualitatively very similar, but are not shown here for the sake of clarity. However, it is obvious that the influence of airframe noise on EPNL increases from sideline to flyover and from flyover to approach. This is due to the respective thrust setting, since this decreases in the aforementioned order. While the airframe has almost no influence on the sideline for all the considered modifications, there are changes in the certification level for flyover when the engine noise is significantly reduced. For the approach, this effect is even more pronounced, and smaller changes are also seen if the engine noise sources remain unchanged.

\section{Application}

\subsection{Novel Aircraft Concepts}

The developed process for the simulation of noise certification is used to evaluate different novel aircraft designs from a previous system noise assessment of a tube-andwing aircraft with geared turbofan engines [2]. In this earlier study, the EPNL certification metric was evaluated on a $30 \mathrm{~km} \times 20 \mathrm{~km}$ grid, but did not take ICAO noise certification regulations (e.g., flight path requirements) into account, which will be done in this study. The aircraft design denotations were adopted from Reference [2]. The aircraft design referred to as zero was selected as a reference aircraft for this study. The aircraft was initally designed in a former DLR project titled "Silent Leading Edge Design" (SLED) (see References $[33,34])$ and has a similar design to the A321 family.

As a reference engine, a two-spool unmixed high-bypass-ratio engine was used, similar to CFM International's CFM56-5A5 engine with a static thrust of $150 \mathrm{kN}$ at sea 
level. The reference aircraft is compared to three aircrafts with different modifications to airframe and engine design. The first modification, referred to as neo, is the replacement of the engine by a modern GTF engine without changing the airframe (see Reference [2] for further details). The second modification, referred to as neo (af), includes the GTF engine in conjunction with a low-noise airframe. In addition, another configuration (fanex) is compared, which is based on a different base aircraft (V2) (see also Reference [2]) and uses the GTF engines in addition to low-noise airframe technology. Here, the two engines are located above the aircraft, at the conjunction of fuselage and wing, in order to shield the engine noise. The aircraft design descriptions, maximum takeoff mass (MTOM) and maximum landing mass (MLM), as well as takeoff and landing speeds, are summarized in Table 4. Further details on the aircraft design studied here can be found in [2].

Table 4. Design aspects of applied aircrafts from previous system noise study [2].

\begin{tabular}{llcccc}
\hline A/C & Description & $\begin{array}{c}\text { MTOM } \\
{[\mathrm{t}]}\end{array}$ & $\begin{array}{c}\text { MLM } \\
{[\mathrm{t}]}\end{array}$ & $\begin{array}{c}\text { Takeoff Speed } \\
{[\mathrm{m} / \mathrm{s}]}\end{array}$ & $\begin{array}{c}\text { Landing } \\
\text { Speed [m/s] }\end{array}$ \\
\hline zero & $\begin{array}{l}\text { Reference aircraft } \\
\text { with reference engines }\end{array}$ & 83,548 & 72,082 & 67.86 & 63.17 \\
\hline neo & $\begin{array}{l}\text { Reference aircraft } \\
\text { with GTF engines }\end{array}$ & 80,076 & 72,868 & 66.70 & 63.47 \\
\hline neo (af) & $\begin{array}{l}\text { Reference aircraft with low } \\
\text { noise airframe modifications } \\
\text { and GTF engines }\end{array}$ & 80,092 & 72,881 & 70.06 & 66.88 \\
\hline fanex & $\begin{array}{l}\text { Variant of V2 (Reference [1]) } \\
\text { with airframe adapted } \\
\text { adapted to GTF }\end{array}$ & 76,218 & 70,187 & 69.35 & 66.67 \\
\hline
\end{tabular}

For better comparability of the concepts, the flight altitude at which the pilot-initiated cutback was performed was kept constant at $500 \mathrm{~m}$ above ground for all configurations. When optimizing the flight path to minimize EPNL at the flyover reference measurement point, the cutback altitude for each configuration was selected so that thrust was reduced shortly before the start of the $10 \mathrm{~dB}$-downtime (integration time of EPNL). In addition, for all configurations, the thrust after cutback was selected so that the aircraft would subsequently continue to fly at a climb rate of $4 \%$.

The noise certification simulation results are shown in Figure 7 for the three configurations neo, neo (af) and fanex relative to the reference aircraft zero. The corresponding lateral measurement position is adapted accordingly for each configuration. The distances from the lateral measurement point (highest EPNL along the takeoff flight path) to the break release point differ between the four configurations. For zero $(2600 \mathrm{~m})$ and neo or neo (af) $(2500 \mathrm{~m})$, there are only minor differences. For fanex, the lateral measurement position is significantly closer to the break release point $(2000 \mathrm{~m})$ as the forward-directed engine noise is shielded by the fuselage and wings. Reductions in certification levels are observed at all three measurement points, with neo and neo (af) showing very similar results. Small deviations may result from different characteristic airspeeds and slightly different aircraft masses. It can be demonstrated that the use of a low-noise airframe in the context of noise certification has only a small advantage. For neo and neo (af), the $10 \mathrm{~dB}$-downtimes are similar to those of the reference aircraft. Due to the fan's tonal contribution, the reference engine has an additional tonal penalty at the sideline measurement point, which does not occur with the GTF engine. This leads to a reduction in the PNLTM.

Due to the effective noise shielding, fanex shows significantly lower certification levels at all three measurement points compared to the zero and the two neo variants. The reductions differ significantly between the measurement points. The noise shielding has the most effective impact on the flyover measurement point, where a reduction of $-16.2 \mathrm{EPNdB}$ occurs. At the approach measurement point, there is a reduction of $-10.9 \mathrm{EPNdB}$ and at 
the lateral measurement point, there is only a reduction of $-4.7 \mathrm{EPNdB}$. Due to the effective noise shielding of the forward-directed engine noise for the fanex, the $10 \mathrm{~dB}$-downtime is significantly reduced, to $9.5 \mathrm{~s}(-51.6 \%)$, compared to the reference aircraft $(18.4 \mathrm{~s})$. This is in conjunction with the slightly reduced PNLTM, by $1.1 \mathrm{~dB}$, to $94.5 \mathrm{~dB}$.

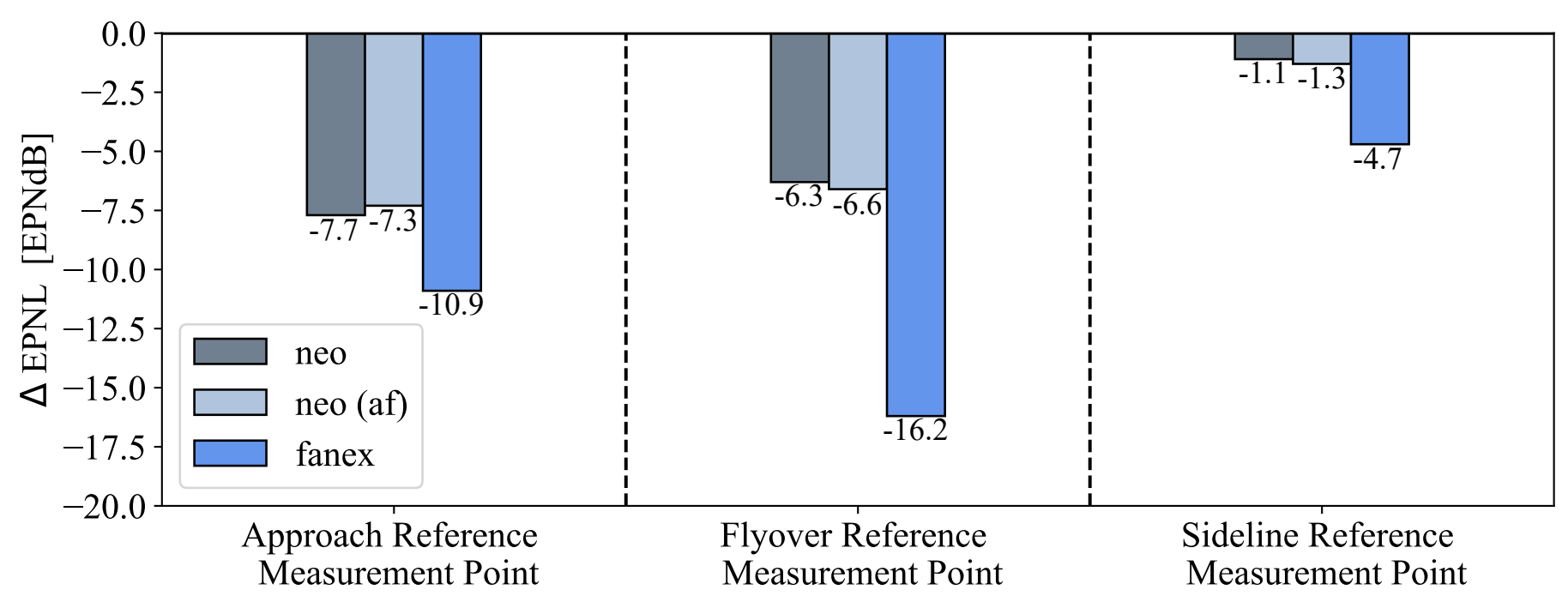

Figure 7. Reduction of certification levels for studied aircraft designs (neo, neo (af), fanex) relative to reference aircraft zero at three reference measurement points Approach, Flyover and Sideline.

For the four aircraft, the margins of the cumulative limits of Noise Chapter 4 are shown in Figure 8. The two neo-variants show similar results, with the a slightly larger margin for the neo (af), with 18.2 EPNdB, compared to the neo, with 18.6 EPNdB. There is only a small margin for zero of $3.7 \mathrm{EPNdB}$, which means that this aircraft was the only one to not achieve a Chapter 14 certification, since, for this, the cumulative limit must be reduced by 7 EPNdB for Chapter 4 to Chapter 14.

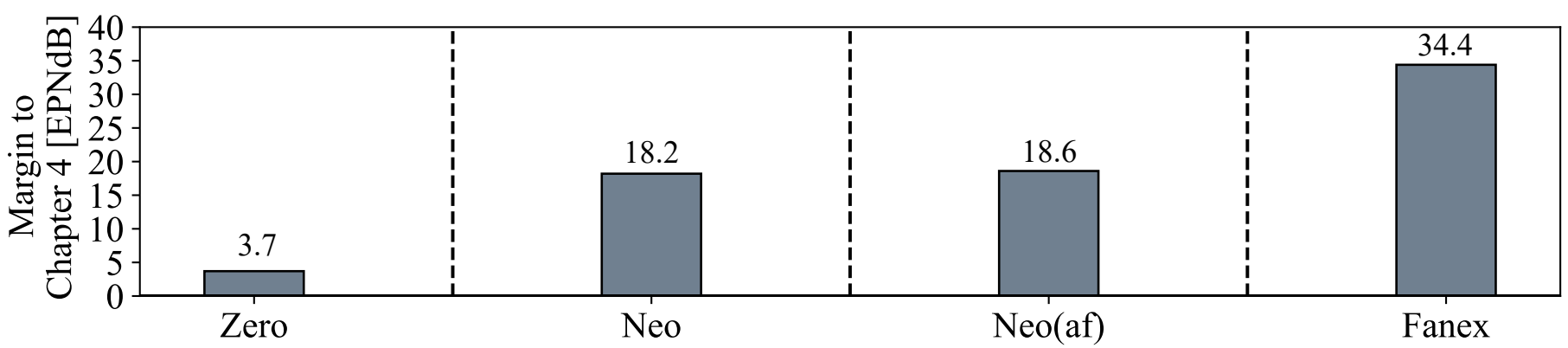

Figure 8. Margin to cumulative Limit of chapter 4 for studied aircraft designs (zero, neo, neo (af), fanex).

It is demonstrated that noise abatement measures for the individual aircraft have different effects on the certification levels. Certification represents only one aspect of the noise assessment of an aircraft during takeoff and landing. The noise-reducing effect of individual measures on the aircraft geometry and engine is only identified at individual measurement points, very close to the runway, and is not considered over a large area. This leads to deviations in the evaluation of individual measures, such as for the low-noise airframe, which shows no significant effect on the certification level in noise certification, although a significant advantage can be demonstrated for large-area contours.

\subsection{Towards Certification Regulations for Supersonic Transport Aircraft}

Recently, noise certification rules for future supersonic aircraft have been presented by the Federal Aviation Agency (FAA) and the Department of Transportation (DOT) [35] 
as a consequence of recent industry activities, e.g., product announcements of supersonic business jet developers such as Boom and Aerion. Again, specific limits for the operation are defined and the EPNL is assessed at the three measurement points. The proposed regulations solely focus on the take-off situation and can be directly implemented into the existing simulation framework to enable a virtual certification process, i.e., under the assumption of constant approach definitions for subsonic and supersonic vehicles. Due to the high thrust requirements for supersonic cruise flight, these SST vehicles use engines with a high specific thrust, tailored to cruise conditions. This results in large excess thrust levels during takeoff, i.e., high jet exit velocities and jet noise generation, as demonstrated by various researchers, e.g., References [36,37]. As a consequence, it can be expected that the direct application of current regulations for subsonic aircraft to supersonic vehicles would result in significantly increased take-off noise levels compared to subsonic transport vehicles, particularly at the lateral measurement point. Therefore, new take-off regulations for supersonic aircraft were proposed by the FAA in order to specifically enable further reductions in take-off thrust settings in proximity to the measurement points and allow for different flight velocities according to the specific SST aerodynamics, e.g., as discussed in Reference [36]. The overall goal of the modifications is to achieve noise certification levels for supersonic aircraft that remain below the published noise limits, applicable to subsonic aircraft of a certain noise category. The discussed rule change regarding take-off, and its influence on certification flight altitude, total thrust and airspeed, are depicted in Figure 9. At the top of this figure, the altitude profiles are shown, commparing subsonic and supersonic aircraft. The first proposed modification focuses on the take-off speed regulations, which are defined relative to the aircraft-specific safe takeoff speed $V 2$. The default speed range is removed, and only the default maximum airspeed of $250 \mathrm{kts}$ is maintained for the SST, to enable a high-speed climb, which can be associated with reduced ground noise impact along the take-off trajectory. According to Reference [36], the higher airspeed reduces the required engine thrust, so that, for the flyover measurement point, the lower thrust should lead to a reduced certification level. This is achieved by a delayed rotation takeoff, i.e., longer acceleration segment on the ground, which can also be seen in the calibrated airspeed profile at the bottom of the figure (from Point A to Point $F^{\prime}$ ). This should enable higher lift-to-drag ratios, and thus optimize flight performance. Furthermore, an additional thrust reduction of up to $10 \%$ before the typical pilot-initiated cutback is being considered, which is not allowed for subsonic aircraft. This modified procedure is called Programmed Lapse Rate (PLR), and was developed in the 1990s [38,39] and applied to SST aircraft by NASA $[36,40]$. This thrust reduction takes place after the obstacle height is reached, and can be seen in the thrust profile in the middle of the figure, between Point C and D'.

No modifications to the subsonic regulations have been proposed with respect to the approach situation to date. However, it can be expected that novel SST vehicles do not have distinct slow flight characteristics, and any installation of a classical high-lift system onboard slim SST wings will be challenging. High-approach velocities can directly translate to increased aerodynamic and fan noise contribution. It is expected that approach noise could become a big challenge for SST vehicles. Only advanced flight procedures, enabled by relaxed regulations and additional low-noise technologies for major noise sources, can relax the noise issue associated with the landing and take-off operation of these vehicles.

The initial implementation of the proposed regulation modifications is intended as a starting point for the evaluation and estimation of certification levels for the new generation of supersonic business jets, which are currently under development. The proposed rule changes, as briefly mentioned here, will then be compared to the current regulations. The impact of these measures on the SST certification levels can then be investigated and discussed. This update will ultimately contribute to the studies that have already been conducted on this research area, to support decision-making in the context of SST certification legislation. 

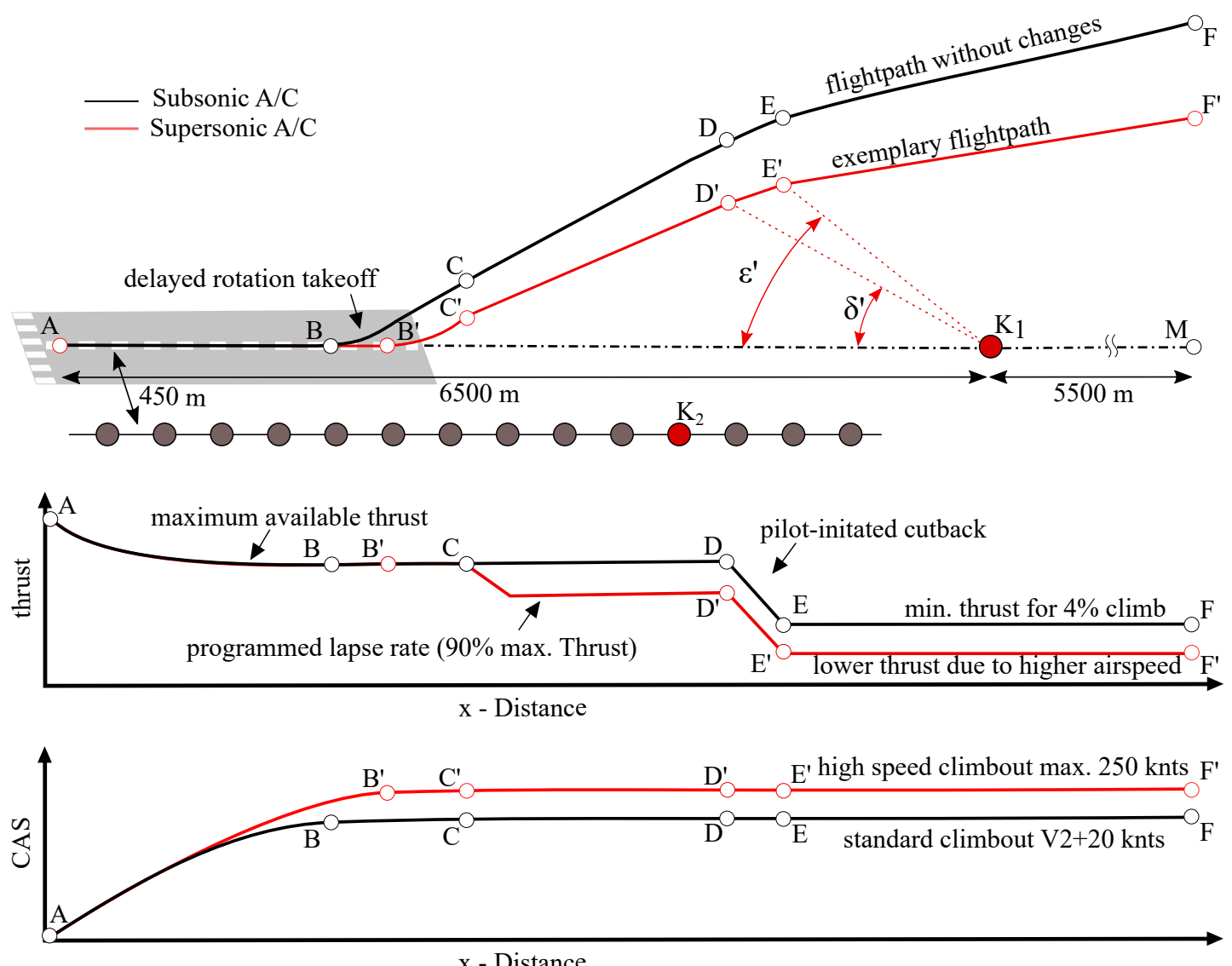

Figure 9. Take-Off reference flight path profile of subsonic and supersonic aircraft for noise certification (top). Changes of thrust (middle) and calibrated airspeed (bottom) profiles for discussed new supersonic noise certification regulations due to high-speed climbout and Programmed Lapse Rate.

\section{Discussion and Conclusions}

This article describes the initial work toward a virtual noise certification process within conceptual aircraft design. An overview of the regulations of ICAO is provided, and a corresponding simulation process is established. It is demonstrated that all the required input information can be made available at the preliminary design phase in order to estimate certification levels and assess the influencing variables. The application of this process to existing aircraft and a comparison of the predicted and published certification noise levels shows discrepancies. A detailed investigation of the influence of all underlying simulation steps is performed and results are presented, including aircraft and engine design, simulation of the flight tracks, and the overall noise prediction methodology. It can be demonstrated that the complexity of the EPNL metric provides difficulties at the conceptual aircraft design phase, and may play a role in the differences. At this phase, only simplified definitions of the actual aircraft design and simplified and semi-empirical noise source models are available. The applied noise source models were specifically developed to enable a comparative assessment of different technologies and aircraft, instead of the prediction of precise absolute levels in complex metrics such as the EPNL. Based on the identified challenges of simulating the certification situation and the prevailing discrepancies with official data, it is recommended that the process only be applied for comparative assessment. The process will predict the noise level differences for technologies under investigation, i.e., aircraft and flight procedure. The impact of novel technologies on the certification levels can be predicted and used to support the decision-making process.

Available simple propagation models furthermore contribute that prediction results are not adequate for a detailed assessment of the spectral information as received on the ground. Comparing prediction results to experimental data (measurements) using different 
and less complex metrics, e.g., A-weighted SPL or SEL, can result in significantly smaller discrepancies, as demonstrated in previous studies, e.g., References [1,41].

However, a direct comparison of prediction results from different simulation tools confirms the reliability of the underlying simulation methods, even for EPNL predictions. Running such different simulation tools based on similar input data results in good agreement between the simulation results [26]. This is a strong indication that much of the experienced discrepancies in the published certification levels is caused by the actual input data, particularly the underlying simulated flight.

In conclusion, at present, it is recommended to only apply the new simulation process to evaluate level differences, instead of absolute levels. Too many uncertainties prevail when comparing the predicted absolute levels with the available certification data, as also experienced by other researchers, e.g., Reference [30]. Due to the lack of information on the precise certification process, i.e., actual flight procedures and availability of all additional corrections to the final results, it is difficult to assess the absolute levels at the certification locations and directly compare these with the available certification data. The process application is, therefore, limited to a comparative assessment of different technologies or aircraft concepts, which was the main goal of these activities. The investigation of different low-noise technologies (e.g., low-noise airframes) reveals that a comprehensive assessment should not only be based on the certification level and metric EPNL at the three representive reference noise measurement points alone. Instead, the assessment should be a holistic evaluation consisting of a large-scale assessment of contours in the vicinity of the airport and multiple noise metrics, e.g., SEL and certification levels, in order to adequately assess the noise issue associated with novel vehicles in conceptual aircraft design.

\section{Outlook}

A revisiting and improvement of the available input data situation and the simulation capabilities is planned in the near future. A better validation of the simulations would result from a comparison with the experimental trajectory data of a valid official noise certification. Typically, the available data from flyover noise measurement campaigns are very limited. Only a few aircraft have been subject to such a detailed and costly assessment, e.g., as described in Reference [17]. In general, the focus of such campaigns does not lie in certification assessment; the goal is to capture the widespread effects of a novel technology on-board the aircraft and/or the effects of novel flight procedures, e.g., Reference [41]. Therefore, the underlying flight procedures usually do not comply with the certification regulations, and, accordingly noise is not measured, i.e., the certification points are not captured or the defined $1.2 \mathrm{~m}$ microphones are not used. Other campaigns capture the defined locations and use the required microphones but do not consider the regulations with respect to the flight procedures, since the research is focused on other aspects, e.g., Reference [31]. In conclusion, such data are most valuable for scientific studies but are not available at present. The assumptions and simplifications regarding the presented simulation of a certification flight can only be verified by a comparison with actual flight data, recorded during a real certification procedure. At this point, it is not possible to fully validate the most important input for the certification simulation, i.e., the actual flight track, which explains the prevailing operating conditions.

The insufficient input data situation can be justified by the assumption of increasing simulation uncertainties. Ongoing research activities toward uncertainty quantification in the context of aircraft noise simulation, e.g., Reference [27], will focus on the certification situation. At the same time, the simulation uncertainties might be reduced by the integration of high-fidelity simulation results into the overall process. Although such high-fidelity methods are typically not available for such an assessment, due to their inherent simulation costs, a mixed-fidelity or multi-fidelty approach and the combination of results is most promising. High-fidelity tools could be applied to confirm the results of the simplified tools, or provide these tools with more reliable input data, and hence improve the overall quality of results. 
Author Contributions: Conceptualization, M.N. and L.B.; methodology, M.N. and L.B.; software, M.N.; formal analysis, M.N. and L.B.; validation, M.N.; writing-original draft preparation, M.N. and L.B.; writing-review and editing, L.B.; visualization, M.N.; supervision, L.B.; project administration, L.B.; funding acquisition, L.B. All authors have read and agreed to the published version of the manuscript.

Funding: The authors gratefully acknowledge a partial funding by the Deutsche Forschungsgemeinschaft (DFG, German Research Foundation) under Germany's Excellence Strategy-EXC 2163/1-Sustainable and Energy Efficient Aviation-Project-ID 390881007. All other funding is associated with DLR internal research activities.

Data Availability Statement: Not applicable.

Acknowledgments: The consulting and support of Jason Blinstrub (DLR) with respect to the flight simulation is greatly appreciated. Furthermore we would like to thank Marc Koch for his assistance with respect to the B747-400 assessment.

Conflicts of Interest: The authors declare no conflict of interest.

\section{Abbreviations}

The following abbreviations are used in this manuscript:

$\begin{array}{ll}\text { C } & \text { sound correction, penalty } \\ \text { CAS } & \text { calibrated airspeed } \\ \text { EPNL } & \text { Effective Perceived Noise level } \\ \text { FDR } & \text { Flight Data Recorder } \\ \text { FLIPNA } & \text { Flightpath for Noise Analysis } \\ \text { ICAO } & \text { International Civil Aviation Organization } \\ \text { MLM } & \text { Maximum landing mass } \\ \text { MTOM } & \text { Maximum takeoff mass } \\ \text { n } & \text { Perceived Noisiness as a function of time and frequency } \\ \text { N } & \text { Total Perceived Noisiness as a function of time } \\ \text { PANAM } & \text { Parametric Aircraft Noise Analysis Module, DLR software } \\ \text { PNL } & \text { Perceived Noise Level as a function of time } \\ \text { PNLT } & \text { Tone Corrected Perceived Noise Level as a function of time } \\ \text { PNLTM } & \text { maximum of Tone Corrected Perceived Noise Level } \\ \text { PrADO } & \text { Preliminary Aircraft Design and Optimization Program } \\ \text { SAE } & \text { Society of Automotive Engineers } \\ \text { SPL } & \text { Sound Pressure Level as a function of time } \\ \text { SST } & \text { Supersonic Transport } \\ \text { Variables: } & \\ \text { A } & \text { break release point } \\ \text { B } & \text { begin transition arch } \\ \text { B }^{\prime} & \text { begin transition arch (SST regulations) } \\ \text { C } & \text { end transition arch } \\ \text { C' } & \text { end transition arch (SST regulations) } \\ \text { D } & \text { begin of pilot-iniated cutback } \\ \text { D' } & \text { begin of pilot-iniated cutback (SST regulations) } \\ \text { E } & \text { end of pilot-iniated cutback } \\ \text { F } & \text { end of reference profile } \\ \text { G } & \text { start of data record for certification } \\ \text { H } & \text { flightposition over approach measurement point } \\ \text { I } & \text { end of glide path } \\ \text { J } & \text { landing point } \\ \mathrm{K}_{1} & \text { flyover reference noise measurement point } \\ \mathrm{K}_{2} & \text { lateral full-power reference noise measurement point } \\ \mathrm{K}_{3} & \text { approach reference noise measurement point } \\ \text { M } & \text { projection from F to ground } \\ \text { O } & \end{array}$




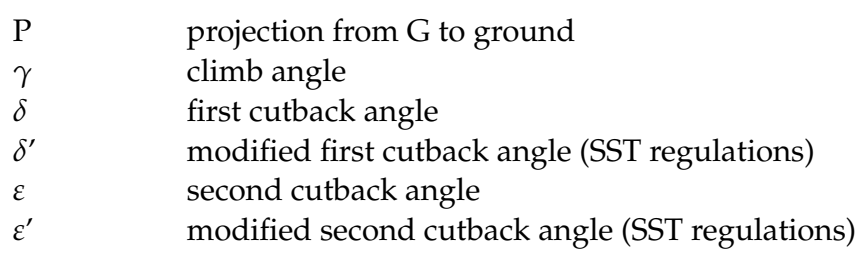

\section{Appendix A}

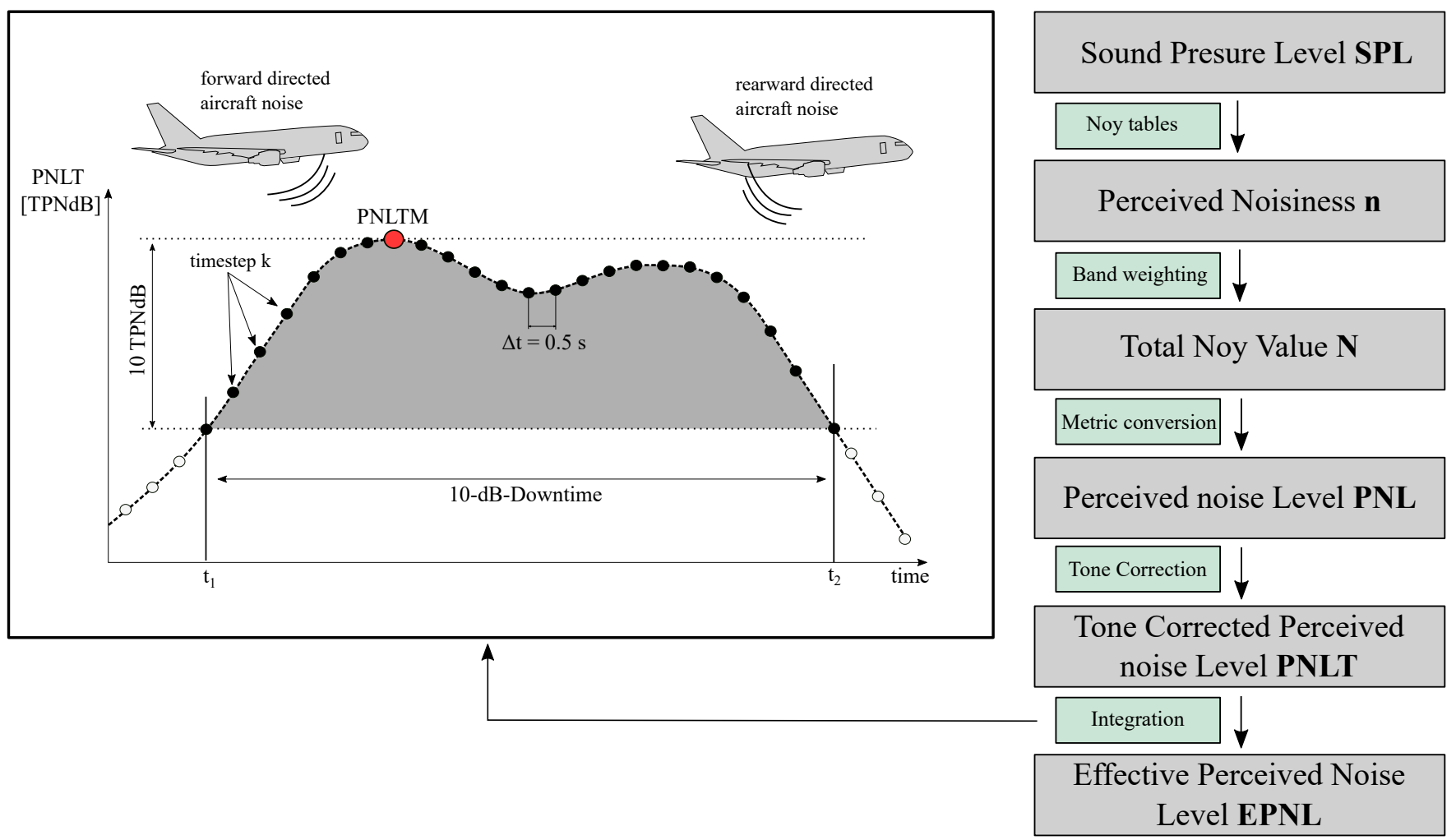

Figure A1. Visualization of Effective Perceived Noise Level Calculation from measured Sound pressure Level.

\section{References}

1. Bertsch, L. Noise Prediction Within Conceptual Aircraft Design; Technical Report DLR-FB-2013-20; Deutsches Zentrum für Luft- und Raumfahrt (DLR): Göttingen, Germany, 2013. [CrossRef]

2. Bertsch, L.; Wolters, F.; Heinze, W.; Pott-Pollenske, M.; Blinstrub, J. System Noise Assessment of a Tube-and-Wing Aircraft with Geared Turbofan Engines. AIAA J. Aircr. 2019, 56, 1577-1596. [CrossRef]

3. International Civil Aviation Organization (ICAO). Environmental Protection. Annex 16 to the Convention on International Civil Aviation. Vol. I, Aircraft Noise, 5th ed.; Technical Report Annex 16; ICAO: Montreal, QC, Canada, 2008; Volume I.

4. Berton, J.; Envia, E.; Burley, C. An analytical assessment of NASA's N+ 1 subsonic fixed wing project noise goal. In Proceedings of the 15th AIAA/CEAS Aeroacoustics Conference (30th AIAA Aeroacoustics Conference), Miami, FL, USA, 11-13 May 2010; p. 3144 .

5. Rizzi, S.A.; Burley, C.L.; Thomas, R.H. Auralization of NASA N+ 2 aircraft concepts from system noise predictions. In Proceedings of the 22nd AIAA/CEAS Aeroacoustics Conference, Lyon, France, 30 May-1 June 2016; p. 2906.

6. Guo, Y.; Thomas, R.H.; Clark, I.A.; June, J.C. Far-Term Noise Reduction Roadmap for the Midfuselage Nacelle Subsonic Transport. AIAA J. Aircr. 2019, 56. [CrossRef]

7. June, J.; Thomas, R.; Guo, Y. System Noise Prediction Uncertainty Quantification for a Hybrid Wing-Body Transport Concept. AIAA J. Aircr. 2020, 58, 1157-1170. [CrossRef]

8. Nöding, M. Virtuelle Lärmzertifizierung im Flugzeugvorentwurf. Master's Thesis, Deutsches Zentrum für Luft- und Raumfahrt (DLR), Göttingen, Germany, 2020.

9. Nöding, M.; Bertsch, L. Beitrag zu einer virtuellen Lärmzertifizierung im Flugzeugvorentwurf. In Deutscher Luft- und Raumfahrtkongress; DLRK: Virtual conference, 2020.

10. ICAO Annex 16: Environmental Protection, Volume I-Aircraft Noise; International Civil Aviation Organization (ICAO): Montreal, QC, Canada, 2011. 
11. ICAO: Environmental Technical Manual, Volume I-Procedures for the Noise Certification of Aircraft; International Civil Aviation Organization (ICAO): Montreal, QC, Canada, 2018.

12. Heinze, W. Beitrag zur Quantitativen Analyse der Technischen und Wirtschaftlichen Auslegungsgrenzen Verschiedener Flugzeugkonzepte für den Transport Grosser Nutzlasten; Technical Report ZLR-Forschungsbericht; ZLR: Braunschweig, Germany, 1994; ISBN 3-928628-14-3.

13. Deidewig, F. Ermittlung der Schadstoffemissionen im Unter- und Ueberschallflug; Technical Report; DLR: Cologne, Germany, 1998. [CrossRef]

14. Blinstrub, J. Immission-Based Noise Reduction within Conceptual Aircraft Design; Technical Report DLR-FB-2019-12; Deutsches Zentrum für Luft- und Raumfahrt (DLR): Göttingen, Germany, 2019. [CrossRef]

15. Dobrzynski, W.; Chow, L.; Guion, P.; Shiells, D. A European Study on Landing Gear Airframe Noise Sources. In Proceedings of the 6th AIAA/CEAS Aeroacoustics Conference, Lahaina, HI, USA, 12-14 June 2000. [CrossRef]

16. Dobrzynski, W.; Pott-Pollenske, M. Slat Noise Source Studies for Farfield Noise Prediction. In Proceedings of the 7th AIAA/CEAS Aeroacoustics Conference, Maastricht, The Netherlands, 28-30 May 2001. [CrossRef]

17. Pott-Pollenske, M.; Dobrzynski, W.; Buchholz, H.; Gehlhar, B.; Walle, F. Validation of Semiempirical Airframe Noise prediction Method through Dedicated A319 Flyover Noise Measurements. In Proceedings of the 8th AIAA/CEAS Aeroacoustics Conference, Breckenridge, CO, USA, 17-19 June 2002. [CrossRef]

18. Rossignol, K.S. Development of an empirical prediction model for flap side-edge noise. In Proceedings of the 16th AIAA/CEAS Aeroacoustics Conference, Stockholm, Sweden, 7-9 June 2010. [CrossRef]

19. Rossignol, K.S. Empirical Prediction of Airfoil Tip Noise. In Proceedings of the 17th AIAA/CEAS Aeroacoustics Conference, Portland, OR, USA, 5-8 June 2011. [CrossRef]

20. Heidmann, M. Interim Prediction Method for Fan and Compressor Source Noise; Technical Report NASA TMX-71763; NASA Langley Research Center: Langley, VA, USA, 1979. [CrossRef]

21. Stone, J.; Groesbeck, D.; Zola, C. Conventional profile coaxial jet noise prediction. AIAA J. 1983, $21,336-342$.

22. Lummer, M. Maggi-Rubinowicz Diffraction Correction for Ray-Tracing Calculations of Engine Noise Shielding. In Proceedings of the 14th AIAA/CEAS Aeroacoustics Conference, Vancouver, BC, Canada, 5-7 May 2008. [CrossRef]

23. International Organization for Standardization (ISO). Acoustics-Attenuation of Sound during Propagation Outdoors. Part 1: Calculation of the Absorption of Sound by the Atmosphere; Technical Report ISO 9613-1:1993; ISO: Geneva, Switzerland, 1993.

24. Society of Automotive Engineers. Prediction Method for Lateral Attenuation of Airplane Noise During Takeoff and Landing; Society of Automotive Engineers: Warrendale, PA, USA, 1981. [CrossRef]

25. Smith, M. Aircraft Noise; Cambridge Aerospace Series; Cambridge University Press: Cambridge, UK, 2004; ISBN 0-521-61699-9. [CrossRef]

26. Bertsch, L.; Sanders, L.; Thomas, R.H.; LeGriffon, I.; June, J.C.; Clark, I.A.; Lorteau, M. Comparative Assessment of Aircraft System Noise Simulation. AIAA J. Aircr. 2021, 1-18. [CrossRef]

27. Bertsch, L.; Schäfer, B.; Guerin, S. Uncertainty analysis for parametric aircraft system noise prediction. AIAA J. Aircr. 2019, 56, 529-544. [CrossRef]

28. Boden, B.; Flink, J.; Mischke, R.; Schaffert, K.; Weinert, A.; Wohlan, A.; Schreiber, A. RCE: An Integration Environment for Engineering and Science. SoftwareX 2021, 15, 100759. [CrossRef]

29. EASA Jet Aeroplane Noise Database for Certification. Available online: https://www.easa.europa.eu/domains / environment/ easa-certification-noise-levels (accessed on 17 April 2021). [CrossRef]

30. Thomas, J.L.; Hansman, R.J. Framework for Analyzing Aircraft Community Noise Impacts of Advanced Operational Flight Procedures. AIAA J. Aircr. 2019, 56, 1407-1417. [CrossRef]

31. Pott-Pollenske, M.; Dobrzynski, W.; Buchholz, H.; Guérin, S.; Saueressig, G.; Finke, U. Airframe Noise Characteristics from Flyover Measurements and Prediction. In Proceedings of the 12th AIAA/CEAS Aeroacoustics Conference, Cambridge, MA, USA, 8-10 May 2006. [CrossRef]

32. Deutsches Zentrum für Luft- und Raumfahrt e.V. (DLR). Leiser Flugverkehr II-Abschlussbericht; Resreport; Deutsches Zentrum für Luft- und Raumfahrt e.V.: Göttingen, Germany, 2007.

33. Pott-Pollenske, M.; Wild, J.; Bertsch, L. Aerodynamic and Acoustic Design of Silent Leading Edge Devices. In Proceedings of the 20th AIAA/CEAS Aeroacoustics Conference, Atlanta, GA, USA, 16-20 June 2014. [CrossRef]

34. Wicke, K.; Bertsch, L. SLED—Silent Leading Edge Devices—Abschlussbericht zum Flugzeugentwurf und der Systemanalyse; DLR Institutsbericht IB-328-2013-30; Deutsches Zentrum fuer Luft- und Raumfahrt: Hamburg, Germany, 2014.

35. Department of Transportation and Federal Aviation Administration. Noise Certification of Supersonic Airplanes; Technical Report; Federal Register, Notice of Proposed Rulemaking (NPRM): Washington, DC, USA, 2021; Volume 85, pp. 20431-20447. Available online: https:/ /www.govinfo.gov/content/pkg/FR-2020-04-13/pdf/2020-07039.pdf (accessed on 20 November 2020).

36. Berton, J.J.; Huff, D.L.; Geiselhart, K.; Seidel, J. Supersonic Technology Concept Aeroplanes for Environmental Studies. In Proceedings of the AIAA Scitech 2020 Forum, Orlando, FL, USA, 6-10 January 2020; p. 0263.

37. Rizzi, S.A.; Berton, J.J.; Tuttle, B.C. Auralization of a Supersonic Business Jet Using Advanced Takeoff Procedures. In Proceedings of the AIAA Scitech 2020 Forum, Orlando, FL, USA, 6-10 January 2020; p. 0266.

38. Shaw, R.J.; Hines, R.; Gilkey, S. Engine Technology Challenges for a 21st Century High-Speed Civil Transport. In the Proceedings of the International Symposium on Air Breathing Engines, Tokyo, Japan, 20-24 September 1993. 
39. Jackson, E.B. Piloted Simulation Assessment of a High-Speed Civil Transport Configuration; NASA Langley Research Center: Langley, VA, USA, 2002. [CrossRef]

40. Huff, D.L.; Henderson, B.S.; Berton, J.J.; Seidel, J.A. Perceived noise analysis for offset jets applied to commercial supersonic aircraft. In Proceedings of the 54th AIAA Aerospace Sciences Meeting, San Diego, CA, USA, 4-8 January 2016; p. 1635.

41. Bertsch, L.; Looye, G.; Anton, E.; Schwanke, S. Flyover Noise Measurements of a Spiraling Noise Abatement Approach Procedure. AIAA J. Aircr. 2011, 48, 436-448. [CrossRef] 